\title{
OIL SPILL DETECTION AND MONITORING OF ABU DHABI COASTAL ZONE USING KOMPSAT-5 SAR IMAGERY
}

\author{
H. A. Harahsheh ${ }^{\mathrm{a}}$ \\ ${ }^{\mathrm{a}}$ Global Scan Technologies LLC \\ hussein.harahsheh@gmail.com
}

Commission VIII, WG VIII/9

KEY WORDS: Remote Sensing, Oil Spill Detection., KOMPSAT-5, Abu Dhabi

\begin{abstract}
:
Abu Dhabi Government endorsed vision for its Maritime Strategy 'A safe, secure and sustainable maritime domain for Abu Dhabi'. This research study share this vision using the concept of monitoring as tool for marine protection against any possible oil pollution. The best technology to detect and monitor oil pollution and in particularly oil spill is SAR imagery In this case study we chose KOMPSAT-5 SAR.

KOMPSAT-5 carries X-band SAR for earth observation, and is capable of day-and-night imaging under all weather condition. It provides three operation modes: High Resolution Mode to provide $1 \mathrm{~m}$ resolution, Standard Mode to provide $3 \mathrm{~m}$ resolution and Wide Swath Mode to provide $20 \mathrm{~m}$ resolution with $100 \mathrm{~km}$ swath at $550 \mathrm{~km}$ altitude, with four modes of polarization. KOMPSAT-5 provides products for various applications; security and defense, mapping, and natural resource management, environmental monitoring, disaster monitoring and more. For our case study we chose to work with Wide Swath mode (WS) with Vertical polarization (VV) to cover a wide area of interest located to the north west of Abu Dhabi including some important islands like "Zirku Island", and areas with oil production activities.
\end{abstract}

The results of data acquired on $4^{\text {th }}$ May 2015 show some spot of oil spill with length estimated about 3 KM, and the daily satellite data acquisition over the period July 24 through July 31 shows serious and many oil spill events some are small, but many others are considered to be big with area size around $20 \mathrm{~km}^{2}$.

In the context of oil spill pollution in the seas, we have to consider the development and increase of overseas transportation, which is an important factor for both social and economic sectors. The harmful effects of marine pollution are numerous, from the damage of marine life to the damage of the aquatic ecosystem as whole. As such, the need for oil slick detection is crucial, for the location of polluted areas and to evaluate slick drift to protect the coastline. Satellite-based oil spill monitoring system now can be used to take precautions and even to determine the possible polluter; it has a vital importance on the detection and protection of national and international waters from the possible damages of petroleum hazard. Finally, and as we suggested in previous studies, we recommend to the national authorities to establish a national near-real time oil spill monitoring system based on SAR satellite imagery, with the support of other tools like AIS and navigation radars 


\section{INTRODUCTION}

In the context of oil spill pollution in the seas, we have to consider the development and increase of overseas transportation, which is an important factor for both social and economic sectors. The harmful effects of marine pollution are numerous, from the damage of marine life to the damage of the aquatic ecosystem as whole. As such, the need for oil slick detection is crucial, for the location of polluted areas and to evaluate slick drift to protect the coastline. Satellite-based oil spill monitoring system now can be used to take precautions and even to determine the possible polluter; it has a vital importance on the detection and protection of national and international waters from the possible damages of petroleum hazard.

Although there is an international trend toward decreasing the numabr and amount of oil spill [3], the influx of oil from tankers and offshore oil operations are serious and consitue major causes of pollution in the marine environment. Environmental. The International tanker Owners Pollution Federation (ITOPF) maintains a database of oil spills from tankers, combined carriers and barges. This contains information on accidental spillages since 1970, except those resulting from acts of war. The data held includes the type of oil spilt, the spill amount, the cause and location of the incident and the vessel involved. For historical reasons, spills are generally categorised by size, $<7$ tonnes, 7-700 tonnes and $>700$ tonnes. Information is now held on nearly 10,000 incidents, the vast majority of which $(81 \%)$ fall into the smallest category i.e. $<7$ tonnes. When looking at the frequency and quantities of oil spilt, it should be noted that a few very large spills are responsible for a high percentage of oil spilt. Over the last two and a half decades, the average number of spills greater than 7 tonnes has progressively reduced by half. In terms of the volume of oil spilt, the figures for a particular year may be severely distorted by a single large incident [10].

The marine environment in the Arabian Gulf region is also under considerable threat from intentional or accidental oil spills, ballast water discharged, dredging and infilling for coastal development, and uncontrolled sewage and industrial wastewater discharges. Oil discharged from ships imposes a much great long-term threat to the marine environment than one big accident. Monitoring illegal oil discharges is thus an important component in ensuring compliance with marine protection legislation and general protection of the coastal environments. There have already been several remarkable accidents involving the loss of large quantities of crude oil from disabled tankers [5].

In the last 20 years, the satellites-borne SAR sensors have been broadly used for oil spill monitoring and have provided excellent data. Their advantages are the capability of wide coverage under any weather conditions all day long, the near real time data delivery and the improved cost-efficiency when compared with airborne SAR surveillance. Some very successful examples of ERS SAR applications in marine oil spill detection have been reported, such as the near-real-time monitoring in Norway [4], monitoring oil spill pollution with ERS SAR in the Mediterranean [20] and the conviction in an oil-spill case in Singapore [13].

The research studies on the use of SAR images on the Arabian Gulf are few, and there is no single study demonstrate the daily capability of monitoring based on high resolution SAR satellite images, this present study consitue the first time of such daily monitoring of oil spill, we should recognize the high performance of KOMPSAT- 5 to achieve such objective. We selected a pilot area, where there is an intensive oil production and related ship movment.

\section{STUDY AREA}

The study area (Figure 1) lies between longitude $52^{\circ} 20^{\prime} \mathrm{E}$ and $54^{\circ} 4^{\prime} \mathrm{E}$, and latitudes $24^{\circ} 30^{\prime} \mathrm{N}$ and $25^{\circ} 36^{\prime} \mathrm{N}$, which covers part of the north west zone of Abu Dhabi

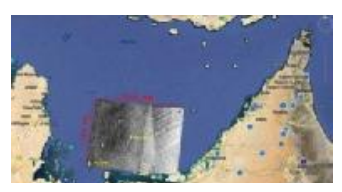

Figure 1: Study area
Island. The dimension is about $160 \mathrm{~km}$ in length and about 120 $\mathrm{km}$ in width, it is a shallow sea water from few meters to around $50 \mathrm{~m}$. Evaporation and wind are major driving forces of water circulation in the Arabian Gulf.

The Arabian Gulf region is the largest offshore oil development area in the world. Bahrain, Iran, Iraq, Kuwait, Qatar, Saudi Arabia, and the United Arab Emirates(UAE) produced over $27 \%$ of the world's oil in 2000 . The area also holds $65 \%$ of the world's oil reserves. The oil sludge, released by tankers cruising in the Arabian Gulf is estimated to be around 8 million metric tons per year, representing $60 \%$ of the total pollution in the area. Oil of about 16 million barrels per day is transported through the strait of Hormuz. Contamination influx is mainly from tankers releasing ballast, tank cleaning leakage from drilling rigs and production platforms, and ship accidents.

\section{DATA SET}

The best technology to detect and monitor oil pollution and in particularly oil spill is "Syntactic Aperture Radar-SAR". In this case study we chose KOMPSAT-5 SAR images (KOrea MultiPurpose SATellite). KOMPSAT-5 mission objectives are the provision of SAR images for GIS applications to support the Korean national environment and disaster monitoring System. KOMPSAT-5 SAR carries X-band synthetic aperture radar (SAR) for earth observation, and is capable of day-and-night imaging under all weather condition. All data are provided and supported by the Korea Aerospace Research Institude and its services organ the SI Imaging services co. ltd. Kompsat 5 provides three operation modes [11]:

1. High Resolution Mode (spotlight mode) to provide 1 $\mathrm{m}$ resolution with $5 \mathrm{~km}$ by $5 \mathrm{~km}$ swath,

2. Standard Mode (strip mode) to provide $3 \mathrm{~m}$ resolution with $30 \mathrm{~km}$ swath and

3. Wide Swath Mode (ScanSAR mode) to provide $20 \mathrm{~m}$ resolution with $100 \mathrm{~km}$ swath at $550 \mathrm{~km}$ altitude,

KOMPSAT-5 provides products for various applications such as security and defense, image interpretation, mapping, land and natural resource management, environmental monitoring, disaster monitoring and more.

In our case study we chose to work with Enhanced Wide Swath mode $(\mathrm{EW})$ with Vertical polarization (VV) to cover a wide area of interest located to the north west of Abu Dhabi including some important islands like "Zirku Island", and areas with oil production activities. This imaging mode allows larger swath in range with respect to the Standard one, but with a less spatial resolution. Enhanced Wide Swath(EW) is focused on improving the radiometric resolution by implementing a dramatic increase of range resolution $(20 \mathrm{~m}$ to $5 \mathrm{~m}$ ) in order to apply a multi-look technique at image processing time (4 looks) which allows 
better image uniformity, in our case study the range resolution is about $7.5 \mathrm{~m}$.

The first set of data acquired on $3^{\text {rd }}$ and $4^{\text {th }}$ May 2015, on standard swath mode and Enhanced wide swath mode and with $1 \mathrm{~m}$ and $7.5 \mathrm{~m}$ resolution respectively. The second set of data acquired on the period of July $24^{\text {th }}$ through July 31 in daily basis, except imaging scheduled in $29^{\text {th }}$ is canceled due to orbit maintenance, these data all acquired on wide swath mode and delivered with $7.5 \mathrm{~m}$ resolution. The table 1 shows the list of these data.

The weather conditions on May $3^{\text {rd }}$ are not favorable to recognize well the oil spill. The wind speed is about $2 \mathrm{~m} / \mathrm{s}$ and this will show the calm water as dark surface, so we decided not to continue the analysis of this data set on May $3^{\text {rd }}$.

\section{IMAGES PREPROCESSING AND PRODUCT LEVEL}

SAR Standard product consists of SAR signal data or SAR image (originated by standard processing of the signal data) distributed on magnetic, optical or electronic media. The standard processing of the KOMPSAT-5 SAR data has been thought to be as much as possible aligned with the definition deriving from literature. The KOMPSAT-5 SAR processors implement four levels of standard processing (from 0 up to level 1D), which a specific output product corresponds to [11].

For the purposes of this study, level 1C were applied to the acquired data, which is detected, geolocated on the reference ellipsoid and represented in cartographic projection (UTM), this product so called GEC_B. The basic processing features characterizing the GEC_B product are[11]:

\begin{tabular}{|c|c|c|c|c|c|c|}
\hline Num & $\begin{array}{c}\text { Actual Imaging } \\
\text { Time }\end{array}$ & $\begin{array}{l}\text { Acquisition } \\
\text { mode }\end{array}$ & $\begin{array}{l}\text { Looking } \\
\text { Mode }\end{array}$ & Pass Direction & Polarization & $\begin{array}{l}\text { Acquisition } \\
\text { status }\end{array}$ \\
\hline \multicolumn{7}{|c|}{ May data acquisition } \\
\hline 1 & 2015-05-03 14:27 & ST & Right & Descending & VV & Delivered \\
\hline 2 & $2015-05-04$ 14:23 & EW & Right & Descending & VV & Delivered \\
\hline \multicolumn{7}{|c|}{ July Data Acquisition } \\
\hline 3 & $2015-07-24$ 14:26 & EW & Right & Descending & VV & Delivered \\
\hline 4 & $2015-07-25$ 14:23 & $\mathbf{E W}$ & Right & Descending & VV & Delivered \\
\hline 5 & $2015-07-26$ 14:19 & EW & Right & Descending & VV & Delivered \\
\hline 6 & 2015-07-27 14:16 & $\overline{E W}$ & Right & Descending & VV & Delivered \\
\hline 7 & $2015-07-28$ 14:12 & $\overline{E W}$ & Right & Descending & VV & Delivered \\
\hline 8 & $2015-07-292: 23$ & & Right & Ascending & VV & Canceled \\
\hline 9 & $2015-07-302: 20$ & $\mathbf{E W}$ & Right & Ascending & VV & Delivered \\
\hline 10 & $2015-07-312: 16$ & EW & Right & Ascending & VV & Delivered \\
\hline
\end{tabular}

Table 1: list of KompSAT-5 data and their characteristics and UTC time acquisition.

- the processing applied for the generation the lower product levels including radiometric equalization with the usage of the ellipsoid for the estimation of antenna pattern and incidence angle)

- multilooking and detection

- $\quad$ for Wide Swath mode only, subswath mosaicking and calibration constant equalization

- the map projection on the ellipsoid

- The data is aligned with the north direction. 


\section{COMPETENCE OF SAR IMAGERY FOR OIL SPILL DETECTION}

The problem of pollution of the oceanic waters by crude oil and oil materials is presently considered as one of the most sharp. As first step for solution of the oil spill response problem is using airborne and spaceborne remote sensing systems for surveillance of the sea surface. Such system must provide the all-weather observation, be independent from of illumination conditions and cloud cover, define the position, type and volume of oil spill and work in real scale of time [24]. Synthetic aperture radar (SAR) is independent of weather and sun illumination conditions and allow to acquire SAR images day and night under cloud cover that is an advantage over other remote sensing sensors.

SAR is an active remote sensing tool in which an antenna on a satellite transmits microwave signals toward to the ocean surface, SAR signal after interaction with the sea surface returns to the antenna [22]. The interaction between the sea surface and microwaves is very sensitive to variations in sea surface roughness. Rough surfaces scatter large amount of energy back to the antenna and have bright signatures while smooth surfaces reflect the energy away from the antenna and have dark signatures. It is well-known, that crude oil and other oil substances form films of various thicknesses on the sea surface. Oil films locally damp sea surface roughness and give dark signatures, so-called slicks, on the SAR images [9];[8], they look on the SAR images as dark patches among brighter surrounding surface.

During the lifetime of oil spill in the sea it will be expose to a number of processes, which dramatically influence physicalchemical properties. Called by term weathering, these processes are as follows: spreading, drift, evaporation, dispersion, emulsification, bacterial degradation and photo oxidation [12]. With time the physical-chemical properties of oil spills are changed due to effect of these processes. These processes play important role in oil spill detection by using space borne SAR, but relative importance of each process is not well understood. It is also reported that the thick part of oil film usually covers only $10 \%$ of spill area, while remaining oil covers up to $90 \%$ of an area as blue shine [22].

The detectability of oil slicks/spills in SAR images strongly depends on the wind speed at the sea surface. Under low wind speeds, typically between 0 and $2-3 \mathrm{~m} / \mathrm{s}$, the sea surface looks dark on SAR images. In this case the wind-generated waves are not already developed and oil films looks dark on a dark background, - detection in this case is impossible. Wind speed between 3 and $6 \mathrm{~m} / \mathrm{s}$ is ideal for oil slick detection, the sea surface roughness is developed and oil slicks appear as dark patches on a bright background. However, when wind speed reaches $10-12 \mathrm{~m} / \mathrm{s}$, detectability is impossible again or obstructed due to the redistribution of oil spills/slicks by the surface waves and wind-induced mixing in the upper ocean layer [23]. as a result slick disappears from the sea surface and SAR imagery.

Other detection problem is discrimination between man-made and natural organic oil slicks [8]. Natural biogenic films of a very small thickness resulting from life-cycle of plankton and other marine organisms can form surface slicks on the sea surface and, in turn, produce similar dark signatures on the SAR images [7]. Experiments conducted with multi-frequency/multipolarization SIR-C/X aboard the space shuttle ([16]; [7]), as expected could provide more reliable information for oil slick discrimination.

\section{METHODOLOGY}

In this study, both visual and digital image processing techniques were applied. The methodology used is shown in the following sections.

\section{Step 1: Oil spill areas identification}

We applied several image enhancement such as linear contract and others, this step allowed us to identify the areas where there are potential oil spills, followed this interpretation we could identified 14 areas, where each has at least one oil spill. This step helped us to focus our following image processing only on the identified areas without the need to process the whole scenes.

\section{Step 2: Image Filtering}

Several filtering methods are used to discriminate high contrast areas representing possible oil spills in the images. In general Lee (7x7), Gamma (7x7), Frost (7x7) and pass (3x3) filters are used in different oil spill discrimination studies (([1], [17], [19]). It is also observed that these filters minimize the loss of information boundaries of high and low contrasted areas. After testing many of these filters, we choose to apply Gamma(7x7) to all sub-images obtained from the first interpretation step.

\section{Step 3: Visual analysis and oil spill digitization}

In order to analyze and interpret correctly the existence and spread of oil spill, it is very important to consider and understand some phenomena and features happing during the oil spill process. Oil spill in the marine environment will immediately start to spread, dispersed or degenerated by natural processes that are collectively called weathering over time. The progress, duration and result of the weathering processes depend on the amount, composition and properties of the spilled oil. Illegal oil slicks from tankers are relatively thin and small in size and they are therefore easier degenerated by weathering in comparison with hazardous accidental oil spill.

As well, we need to consider the environmental conditions such as mixing, currents, temperature and sunlight are also important for the weathering of spilled oil [15]. As weathering processes impact on the spill during the first few hours after dumping, it is very important to detect the first and new oil spill, then it is crucial to have a continuous, hours or daily detection system. Large amounts of oil will result to large spills, usually within a short time after dumping. On the other hand oils with large volatile and dissoluble in seawater content will result to smaller spills, in comparison to those with less such content, when spilled in the same amounts [22]

Also in our interpretation we consider the look-alike phenomena that appear under sea-air boundary layer conditions, which may be classified as oil spill in radar images. These may include, natural slicks threshold winds, wind shadows behind islands, winds slicks (calm zones), surface currents, internal waves, reflections of

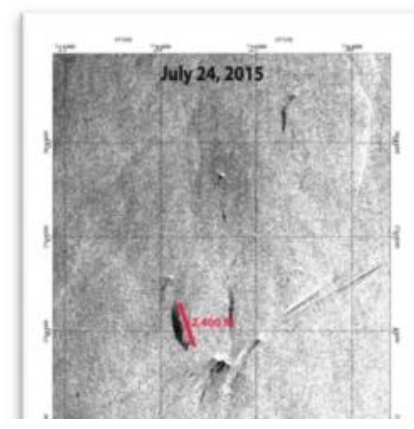

Figure 2: Oil Spill Map from July 24 KompSAR- 5 
the bottom topography in shallow waters, fresh water slicks, plums of municipal sewage, wave shadows behind land or structures [19].

In each oil spill area identified, there are several oil spills, we could map and digitize each one, then this followed by calculation of the area size, and create oil spill map (Figure 2),

We used several remote sensing "image processing" software in particularly Geomatica 15 and ENVI 5.1, as well we found Google Earth is a user friendly tool to visualize the results and analyze it through the acquisition period.

\section{ANALYSIS AND RESULTS}

Analytical efforts were focused on overall assessments of image quality and suitability for slick detection, identification of possible oil slicks in the area, and comparison of slick patterns between the different dates of imagery. The interpretation results indicate that certain coastal areas of the UAE face frequent oil spills.

The daily acquisition of KOMPSAT 5 SAR images over the study area allowed us to identify three areas with frequent oil spill incidents, and two areas with less frequency. From our analyzing of these areas of oil spill we could see the evolution and the progress of oil spill.

\section{General:}

In total and through the 8 dates of data acquisition and oil spill monitoring we could identify 73 oil spills distributed through 14 areas of oil spill. These are concentrated mainly in three regions, and there

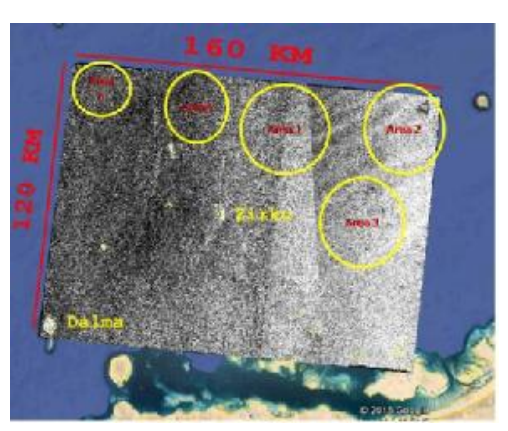

Figure 3: location map of oil spill region in the study area are two others with less frequency, and they are located with Qatar marine area (Figure 3).

The total areas calculation is about 91.6 $\mathrm{km}^{2}$, but we need to consider only the average per aquistion or per day. as well we Assume oi in average 3500 litrs

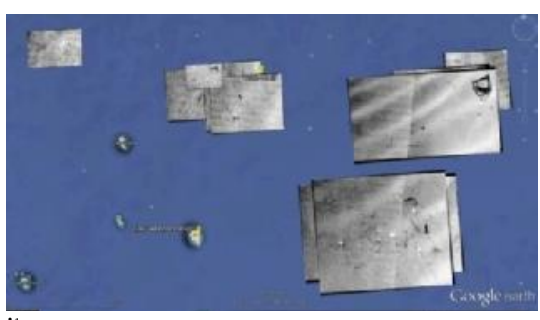

Figure 4: Main area of oil spill from all data set

we conclude that the total oil spill $32.55 \mathrm{~km} 2$ will spread 101 tons, and in this case we have the following estimation per area (Table 2 and Figure 4):

Table 2: Area size with estimated metric ton

\begin{tabular}{|l|l|l|}
\hline $\begin{array}{l}\text { Area } \\
\text { nbr }\end{array}$ & Size in km2 & $\begin{array}{l}\text { Estimated metric } \\
\text { ton(ton) }\end{array}$ \\
\hline 1 & 1.85 & 5.7 \\
\hline 2 & 20 & 62 \\
\hline 3 & 8 & 24.8 \\
\hline 4 & 1.7 & 5.3 \\
\hline 5 & 1 & 3.1 \\
\hline total & 32.55 & 101 \\
\hline
\end{tabular}

Looking to the AIS map information (https://www.vesselfinder.com), which is freely available shows clearly the concentration of varias type of ship/vessel in the areas, and in particularly in these areas; 1, 2 qnd 3. Type of ships include crude oil tankers, Tug/supply vessel, or support vessel, and other type of ship. Using this service of AIS tracker is very helpful for the investigatation about an accident, and the analyse of vessel behaviour patterns for potential prosecution of illegal actions, such as

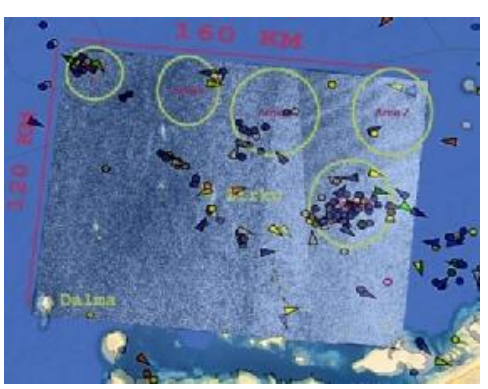

Figure 5: reprojection of AIS Information on the illegal ballast water exchange or illegal bunkering(Figure 5).

In the area 1 we have 9 data acquisition, two in May and 7 in July, we have identified oil spills in all of these data sets, exepct the data of May 3rd for the weather reasons mentioned previously, and on July 28, although the data is very good and the weather condition are favorable for oil spill detection, where the wind speed around $6 \mathrm{~m} / \mathrm{s}$ and the wave hieght 3 feets, nevertheless we didn't identified any major or recongizable oil spill. It could reflect less activtie of ship movment, or a firm coast guard patrol activities in that day, we think this needs more invistigation!

Considering the behavior of the varias oil spill identified through the observation, we can say the life cycle of an oil spill vary from few hours to few days, and this depend on the type of oil and the size or quanity as well the weather conditions such as current and wind speed and their directions. In the region we identified mostly small oil spills, about 30 oil spill (out from a

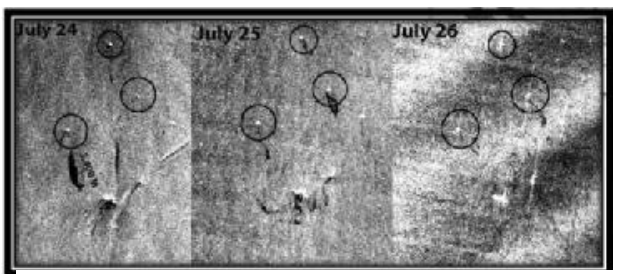

total 73 spill Figure 6: Analysis and comparison of three identified), and as most of these are successive data contained oil spill 
small and most propably are very light crudes and light refined products (e.g., gasoline and diesel) will quickly spread into very

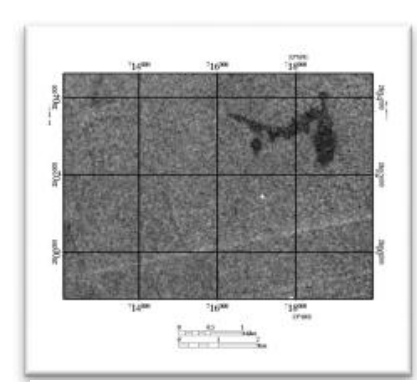

Figure 7: Important oil spill identified on July thin films when spilled (reference aerial-obervation).

Analyzing the successive three days on the area number one, we see how fast the dispersion of the oil spill, and this means almost every day there are several of oil

release in the water, and all disappear deep in the gulf marine water, which definitively affect and damage the marine life. We nofity that the length of such spill reach thousands of meters and hundreds of width Figure 6

Although most of the spills in this area are small, still there are some with important size like the one identified in this region on July 31,2015 . It is about $2.32 \mathrm{~km} 2$, which could released more than 7 tons of oil!(Figure 7).

In the area 2 we identified a big oil spill and other smaller ones similar to the spill identified in the area 1 .

It is very clear this is a serious oil spill that spreaded over $14 \mathrm{~km}^{2}$, and most propabley it was released on July $25^{\text {th }}$, seeing the rapid progress and development of the spill through the follwing days. From the dark color of the spill on $25^{\text {th }}$ and $26^{\text {th }}$, it

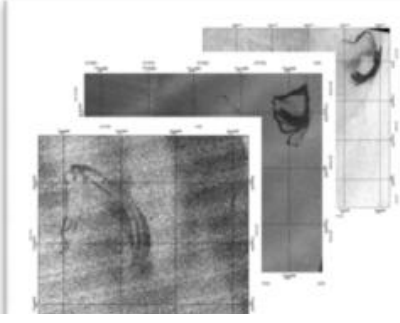

Figure 8: A serious oil spill covering an area more than 14 $\mathrm{km} 2$ is like a fresh oil spill, and within few days (the image of July 31 ), the spill started to disappear in the water causing a lot of damage to the marine life. we can expect the life cycle of this big oil spill would go from July 24/25th to August 5th, which means about days! we didn't notify any announcment about this incident from any media in the Gulf, we have have to say it is far from the coast of Abu DHabi, it is about $85 \mathrm{~km}$, but not far from Sir Bu Nair Island, it is close by about $20 \mathrm{~km}$, this is a serious distance (Figure 8)

The movement of the this spill and its direction are controled by local climate condition in particularly the wind and current,

but we observed, it didn't travel much and it developped almost in the same region (Figure 9).Finding such as this big oil spill, and considering all its environmental and economic damage necessitate a continous monitoring of this sensitive environment.
The area 3 is very similar to the first area, it is an area, where there is an intensive movment of ships from different kinds, and these normal

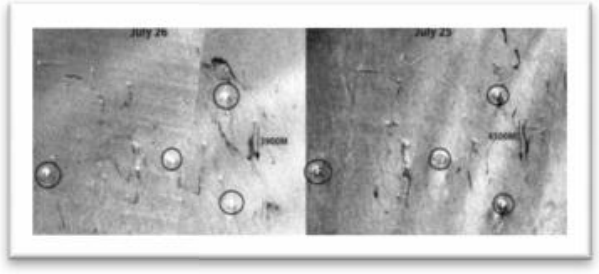

Figure 10: comparison of two successive days, where many daily oil spills are occuring seeing the number of oil production platforms in this area. The size of oil spills are important in size, we can see oil spill with lenth about $5 \mathrm{Km}$. although the number and spread are important, where we observed around 20 spills, we noted the life cycle of these spills are from few hours to two days. the total size of oil spills in this area is about $8 \mathrm{~km}^{2}$ (Figure 10).

\section{CONCLUSION}

We conclude that remote sensing technology including the use of SAR imagery is very crucial for an effective detection and monitoring of oil spill. The importance of satellite imagery in its large coverage, the high frequency of acquisition, as we have demonstated a daily coverage and it could be less than daily with the help of more than one satellite. KOMPSAT 5 SAR proved its capability to detect clearly oil spill, its high resolution helped us to identify even the very small oil spill $\left(0.06 \mathrm{~km}^{2}\right)$, and the high frequency of data aquistion, where it provided us with daily coverage, helped us to achieve these results. In addition it is now very easy to aquire the data and deliver the oil spill report in less than one hour, and adding the information of AIS, which give information about the potential polluters, we can claim a near real time oil spill monitoring system.

The big number of oil spills, where we found daily small oil spills events, is a clear evidence of the problem in this region, we linked this as well to the intensive movment of ships, and in particularly for the supply and support vessels for the oil production platforms. This indicate as well the main causes of oil spill are the illegal actions, in particularly from the discharge of ballast water and the bunkering activities.

We notified the rapid disappear of the small oil spill, may be only few hours, but the bigger ones could stay more than ten days, all depend on the size and the typ of materials, this could be crude oil or ligh diesel.

Finally, and as we suggested in previous studies, we recommend to the national authorities to establish a national near-real time oil spill monitoring system based on SAR satellite imagery, with the support of other tools like AIS and navigation radars.

\section{Acknowlogement}

The author express his gratitude to the Korea Aerospace Research Institude and its services organ the SI Imaging services co for providing the SAR data set, as well for their great technical support. The author as well thank GISTEC, the 
official distributor of Geomatica software, for the support of using the latest version of PCI. Also, we would thank the "National Center of Meteorology \& Seismology" for providing climate data reports.

\section{References}

1. Akkartal A., F. Sunar,. The usage of radar images in oil spill detection, The International Archives of the Photogrammetry, Remote Sensing and Spatial Information Sciences. Vol. XXXVII. Part B8. Beijing 2008, pp. 271-276(2008)

2. Alpers, W., and H. Huhnerfuss.. Radar signatures of oil films floating on the sea surface and the Marangoni effect.J.Geophys. Res., 93, 36423648(1988).

3. Etkin, D.S., Analysis of oil spill trends in the US and worldwide 2001. Proceedings of the 2001 International Oil Spill Conference, pp. 1,291-1,300 (2001).

4. Espedal, H.A., O.M. Johannessen, J.A. Johannessen, et al. COSWATCH'95 ERS 1/2 SAR detection of natural film on the ocean surface. J. Geophys. Res., 92, 24969-24982, 1998.

5. Essa. s. m., Harahsheh. h., Shiobara. m., and Nishidai. t, Operational Remote sensing for the Detection and Monitoring of oil Pollution in the Arabian Gulf: case studies from the united Arab Emirates. Oil Pollution and its Environmental Impact in the Arabian Gulf region. M. AlAzab, W. Elshrbajy and S. AL-Ghais, (editors). ELSEVIER. Development in Earth \& Environmental Science 3, pp: 31 - 48(2005).

6. Gade, M., W. Alpers, H. Huhnerfuss, et al. Imaging of biogenic and anthropogenic ocean surface films by the multifrequency/multipolarization SIR-C/X-SAR. J. Geophys.Res., 103, 18851-18866(1998)

7. Gade, M., and S. Ufermann. Using ERS-2 SAR images for routine observation of marine pollution in European coastal waters. Proc. of IGARSS'98, Seattle, USA, July 6-10(1998).

8. Huhnerfuss, H., Alpers W., Fast O., et al. 1986. On the discrimination between crude oil spills and monomolecular sea slicks by airborne remote sensors - today@s possibilities and limitations. Proc. Of IGARSS@86, Zurich,1359-1364(1986)

9. Huhnerfuss, H., W. Alpers, W.L. Jones, et al. The damping of ocean surface waves by a monomolecular film measured by the wave staffs and microwave radars. J. Geophys.Res., 86, 429-438(1981)

10. ITOPF,http://www.itopf.com/fileadmin/data/Docume nts/Company_Lit/Oil_Spill_Stats_2014FINALlowres. pdf)(2015).

11. Korea Aerospace Research Institude(KARI), SI Imaging services co., ltd, kompsat-5 product specifications/ standard products specifications, version 1.2, july, 2015.

12. Kotova, L., H.A. Espedal, and O.M Johannessen. Oil Spill Detection Using Spaceborne SAR: a Brief Review. Proc. 27 th Int. Symposium on Remote Sensing Environmental, 8-12 June 1998, Tromso, Norway, 791-794(1998).

13. Lu J., H. Lim, M. Bao, S.C. Liew, L.K. Kwoh, 1999. Mapping ocean oil pollution with ERS SAR imagery, Proc. 20th. Asian Conf. Rem. Sens., 22-25 November, Hong Kong, China. http://www.aars-
acrs.org/acrs/proceeding/ACRS1999/Papers/OCN994.htm(1999).

14. LU, J, Marine oil spill detection, statistics and mapping with ERS SAR imagery in south-east Asia, International Journal of remote Sensing, 24,15, 30133032 (2003).

15. Maar M., Burchard H. \& Bolding, K. "Simulating the fate of illegal oil discharges in the marine envronment, deliverable report \#7" (2003), http://pta.jrc.cec.eu.int/

16. Masuko, H., T. Kobayashi, K. Okamoto, and W. Alpers. Observation of artificial slicks with SIR-C/XSAR around Japan. Proc. IGARSS@95, Florence, Italy, 14-18 July 1995, P.227-229(1995)

17. Marghany, RADARSAT Automatic Algorithms for Detecting Coastal Oil Spill Pollution, International Journal of Applied Earth Observation and Geoinformation, Vol. 3, Sayi 2, pp. 191-196 (2001)

18. National Center of Meteorology \& Seismology, climate data report by personal request, $\mathrm{p} 4(2015)$

19. Özkan C., F. Sunar, Comparisons of Different SemiAutomated Techniquesfor Oil-SpillDetection:A Case Study in Lebanon, 27th EARSel Symposium, 47 June, Bolzano, Italya (2007). http://www.researchgate.net.

20. PAVLAKIS, P., SIEBER, A., AND ALEXANDRY, S., Monitoring OilSpill Pollution in the Mediterranean with ERS SAR. Earth Observation, Quarterly, 52, 811(1996).

21. Pavlakis, P., Tarchi, D., Sieber, A.J., 2001, On the Monitoring of Illict Vessel Discharges, A Reconnaissance Study in the Mediterranean Sea, EC DG Joint Research Center, Institute for the Protection and Security of the Citizen Humanitarian Security Unit (2001). http://ec.europa.eu/echo/files/civil_protection/civil/ma rin/reports_publications-/jrc_illicit_study.pdf

22. Sabins, F., Remote sensing - Principles and Interpretation. W.H. Freeman \& Co, N.Y. 494 p, 1997.

23. Scott, J.C. 1986. Surface films in oceanography. ONRL Workshop Rep. C-11-86. Office of Nav. Res., London, 19-34(1986)

24. Witte, F. Oil slick detection with a side looking airborne radar. Proc. of IGARSS@86, Zurich, 8-11 Sept. 1986, 1369-1374,1986 